\title{
ASSESSMENT OF HERBAL PLANT BIOFUEL PELLET QUALITY INDICATORS
}

\author{
Algirdas JASINSKAS, Institute of Agricultural Engineering and Safety, Faculty of Agricultural Engineering, Aleksandras Stulginskis \\ University, Studentu g. 15, Akademija, LT-53362 Kaunas raj., Lithuania, algirdas.jasinskas@ asu.lt (corresponding author) \\ Egidijus ŠARAUSKIS, Institute of Agricultural Engineering and Safety, Faculty of Agricultural Engineering, Aleksandras \\ Stulginskis Universitỵ, Studentu g. 15, Akademija, LT-53362 Kaunas raj., Lithuania, egidijus.sarauskis@ asu.lt \\ Asta GUTAUTAITE், Institute of Agricultural Engineering and Safety, Faculty of Agricultural Engineering, Aleksandras \\ Stulginskis University. Studentu g. 15, Akademija, LT-53362 Kaunas raj., Lithuania, asta.gutautaite@ gmail.com \\ Jiří MAŠEK, Faculty of Engineering, Czech University of Life Sciences Prague, Czech Republic, Kamycka 129, CZ - 16521 , \\ Prague 6 -Suchdol, Czech Republic, masekj@tf.czu.cz
}

\begin{abstract}
Variety of vegetable raw materials is used for energetic needs: logging and wood processing waste, agricultural production byproducts: straws as well as specially cultivated trees, tall grass, rapeseeds, triticale and other herbaceous plants. In the performed scientific work, preparation and opportunities of use of energetic needs are estimated for non-conventional energy plants (elephant grass, orchard grass, common mugwort and fibrous nettle), technological parameters of processing these seeds and pressing into granules are explored, biometric and physic-mechanical properties of finished pellets are evaluated, and their resistance to impact forces is evaluate. Having examined humidity of pellets, it was found that maximum moisture content was in pellets of elephant grass and nettle - from 13.1 to $13.2 \%$, while the smallest - in orchard grass pellets $10.0 \%$. The largest density of non-conventional energetic pellet density was orchard $-983.8 \mathrm{~kg} \mathrm{~m}^{-3} \mathrm{DM}$ (dry matter) and common mugwort $-926.7 \mathrm{~kg} \mathrm{~m}^{-3} \mathrm{DM}$, and density of elephant grass pellets was the lowest $-619.3 \mathrm{~kg} \mathrm{~m}^{-3} \mathrm{DM}$. Results on resistance to deformability of non-conventional energetic crops granules indicate that the highest resistance against external forces is a pellet made of common mugwort: they decompose to $110.03 \mathrm{~N}$ force. Pellets of other plants disintegrate to smaller external force: fibrous nettle granules - to $90.6 \mathrm{~N}$, orchard - to $67.3 \mathrm{~N}$ force. Elephant grass pellets have the smallest resistance to deformation and decompose more quickly (at $20 \mathrm{~N}$ ). The research results show that pellets made of elephant grass are of the lowest quality; due to this, it is not recommended to use these plants in the form of pellets.
\end{abstract}

Keywords: energy plants, pellets, properties, compression resistance

\section{INTRODUCTION}

Plant biomass such as wood, straw, energy crops is one of the most important renewable energy source in Europe and Lithuania and now account for a considerable share of local fuel (Sakalauskas et al., 2012). In Lithuania, the start of biofuel production began in 1994 taking over the Scandinavian countries' experience in the boiler room fired with biofuels (chipped wood and sawdust). They are particularly successful in those regions of the country where thermal energy was used to produce expensive and highly polluting fuel - fuel oil. As a new industry, biofuels production in the country has established itself in 1999, put into service on the lar ger-fired boiler plants (Biekša et al., 2007).

Nowadays, various vegetable raw materials are used for energy needs: logging and wood processing waste, agricultural production by-product - straw, as well as specially cultivated trees, tall grass, rape, triticale and other unconventional energy plants - elephant grass, orchard grass, plain wormwood, nettle, etc.

Having examined a row of scientific research (Verbickas et al., 2013), it can be said that it is necessary to rapidly expand energy crop plantations, not only of woody but also perennial herbaceous plants. In the unused land areas, it would be purposeful to grow traditional, in Lithuania well-growing and well-adapted to the climate, used for animal feed herbs (preferably of Poaceae family). The most productive growing in Lithuania grass is reed canary grass, bromegrass, festuca. These species produce 5.0 to $15.0 \mathrm{t} \mathrm{ha}^{-1}$ of dry biomass. Overgrown or grass unused for feed (which accounts for about $15 \%$ of feed cultivated grass) and flooded meadow grass may be used for energy purposes (Genutis et al., 2006).

In assessing the potential of Lithuanian vegetation, it may be stated that that we have a relatively favourable climatic conditions for the majority of plant species, which is largely determined by the type of plant potential. Global and 
local climate, breeding progress and the latest technology suggest that plant species that are abundant these days are not prevalent or completely free marketplace in the future will be biologically, economically and ecologically significant.

Elephant grass (Miscanthus sinensis) is a perennial herbaceous plant of aceae (Poaceae) family; it is with shiny, leaning leaves that grows to 2.5-3 m, sometimes even up to 4 meters high, also known as Chinese reed (Burbulis et al., 2012). The research of the German scientists has shown that water makes the greatest impact on elephant grass harvest. Under favourable growing conditions or additional watering of crops may get additional harvest. Elephant grasses is capable of producing up to $25 \mathrm{t} \mathrm{ha}^{-1}$ of dry matter and accumulate 10-20 t ha-1 of rootstock mass. The stalks of these plants for fuel can grow in the same area for 20-25 years. Elephant grass biomass is hypo-caloric: $1 \mathrm{~kg}$ of dry biomass produces $17 \mathrm{MJ}$ of energy, i.e. 20 tons of grass serves as 8 tons of coal.

The experience of Czech scientists shows that the main drawback of elephant grass - sensitivity to cold, especially in the first year of growth. If during the first year a colder winter occurs, crop may become thinner or even die completely. Based on scientific data and taking into consideration Lithuanian climatic conditions, especially rainfall, it can be assumed that it should be favourable for elephant grass to grow in Lithuania (Jasinskas et al., 2008).

Orchard grass (Dactylis glomerata) is a herbaceous plant of Poaceae family of orchard grass (Dactylis). It grows in meadows, glades, outskirts, fertile soils (Christian et al., 2012). It is a perennial plant, forming large spells, which fully grow in the third year. It is usually sown and cultivated in the cultural meadows. It re-grows very well after mowing, but begins to wilt if over grazed. Grasslands are evaluated by their fertility and longevity, but these are not the only indicators. Herbs used in the production of feed are assessed according to their nutrition; mainly orchard grass is grown for animal feed preparation (My farm, 2011). Orchard grass wider use is unknown. Due to the high yield and nutritional indices, this grass is adapted for solid biofuel and biogas production.

Common mugwort (Artemisia vulgaris L.) is Asteraceae family genus. The plant is common in Europe and the Mediterranean region. The genus contains about 250 species. 11 kinds grow in Lithuania; most common of them are wormwood (A. abrotanum), wormwood (A. absinthium), tawny (A. campestris), tarragon or otherwise called, tarragon (A. dracunculus) and Artemisia vulgaris (A . vulgaris) (Kryžiavičienè et al., 2010).

In the published sources of the US and Britain, common mugwort are attributed to future plants due to their wide range of applications in the food industry and medicine (Common mugwort, 2014). It is known that Artemisia vulgaris reduces spasms, fever, skin inflammation, relieves abdominal colic, improves appetite, cures rheumatism. The rich chemical composition of this genus determines its exceptionally high biomass combustion, which since ancient times has been observed in plants, and plants have been used for bonfires establishment (Kryžiavičienė et al., 2010). Fibrous materials are also found in biomass.

Nettle (Urtica) is a well-known perennial herbaceous plant that can grow long in suitable spot and be productive for about 10 years. This is a common plant that grows like a weed in the bush, polluted areas, by the fence. Apart from stinging nettle (Urtica dioica), in Lithuania also grows stinging (Urtica urens) and hemp (Urtica cannabina) nettle. This plant is propagated by seeds, root suckers and stem pieces (Johnson, 1992).

In the testing station Upyte of the Lithuanian Research Centre for Agriculture and Forestry (LRCAF) branch, studies on cultivation and propagation of fiber nettle have been performed since 2007 (Jankauskiene et al., 2010). In the test station, nettle fibre is propagated by stem cuttings. Compared to flax, nettle fibre is thinner; due to its glossy appearance, it is often blended with other natural and synthetic fibres. Often in the literature nettle fibre anti-allergic and absorbent properties are highlighted (Nettle..., 2012). Fiber content of nettle stems depends on the growth conditions (natural plant or specially produced). Austrian, German, British and Finnish researchers are very interested in usage of nettle fibre. Various researches to evaluate the use of nettle for energy needs have been conducted.

The aim of this work is to explore non-traditional plants: elephant grass (Miscanthus sinensis), common mugwort (Artemisia vulgaris), orchard grasses and fibrous nettle on the preparation and use for bio-fuels and determination of biometrical and physic-mechanical properties of plant granules and their qualitative indicators.

\section{MATERIALS AND METHODS}

Pellet production. Pellet production technology and equipment depends on the raw material, fractional composition and moisture content. Various herbaceous plants grown in the fields of the Lithuanian, Lithuanian Research Centre for Agriculture Institute, Branch of Vėžaičiai and test station Upyte, were used to tests: elephant grass, fibrous nettle, common mugwort and orchard grass. Grinding drum was used for grinding of stems of these energy plants, for milling - a hammer mill and for granulation - low productivity pelletiser with a horizontal array, diameter of a granule is $6 \mathrm{~mm}$ (Jasinskas et al., 2014).

Granulation technology is divided into four zones:

- Preparation of raw material-storage;

- Drying;

- Granulation;

- Packing of pellets-storage.

The conditioning process is carried out before the minced plant biomass gets into the granulator. During conditioning process, crushed biomass is mixed thoroughly to achieve homogeneity of the raw materials and similarity of properties of the produced pellets. Then the raw material is moistened (if it is too dry for granulation). This is done for stirred biomass by spreading water. 
Pellet production press is used for pellets' production in which crushed and milled biomass is moved by the rollers through matrix holes $(6 \mathrm{~mm})$. After granulation stabilization period starts. During this stage, formation of some of the properties of pellets takes place: moisture content, hygroscopicity, strength. During pressing, the granules may get heated up to $70-90^{\circ} \mathrm{C}$; they have therefore to be cooled. Special equipment is used for cooling pellets - cooling chamber in which they are ventilated by force with ambient air.

Biometrical parameters. The milled energy plants were granulated by a small capacity $\left(100-120 \mathrm{~kg} \mathrm{~h}^{-1}\right)$ granulator with a horizontal granulator matrix. The diameter of the pellets was $6 \mathrm{~mm}$. The mill was granulated in the traditional way: before the mill entered the granulator, the mill was mixed thoroughly to achieve homogeneity. Next, the raw material was moistened (if it was too dry for granulation), and the dosage unit was supplied to the press chamber, wherein the mill was moved by rollers through the matrix holes of $6 \mathrm{~mm}$ diameter. The biomass was pressed through holes to form pellets.

When the pellets cooled, their biometric parameters: dimensions, moisture content, volume and density, were evaluated (Introduction..., 2013). The pellet parameters were determined by measuring their height and diameter (accurate to $0.05 \mathrm{~mm}$ ). Experimental trials were randomly selected for each plant species with 10 pellets.

Pellets weight was assessed by KERN ABJ scales (accurate to $0.001 \mathrm{~g}$ ). The weights were calculated for each type of plant using 10 of the granules with the average meaning the error.

Pellets moisture content was determined in a laboratory drying chamber oven according to the standard method (Introduction..., 2013).

Pellets density. The pellet volume was calculated using the pellet size (diameter and length). After determination of pellet mass and volume there are calculated their density.It also has been determined the bulk density of pellet, granules poured into $3 \mathrm{dm}^{3}$ container, weighing and calculating the bulk density.

Pellet compressive strength. When producing pellets of non-conventional energy crops, binders have not been used. INSTRON testing equipment in Aleksandras Stulginskis University (ASU), Agricultural Engineering and Safety Institute, was used for examination of pellet compressive strength (Figure 1). Tests were carried out by placing fuel pellets on a horizontal plane (table) and pressing by vertical load.
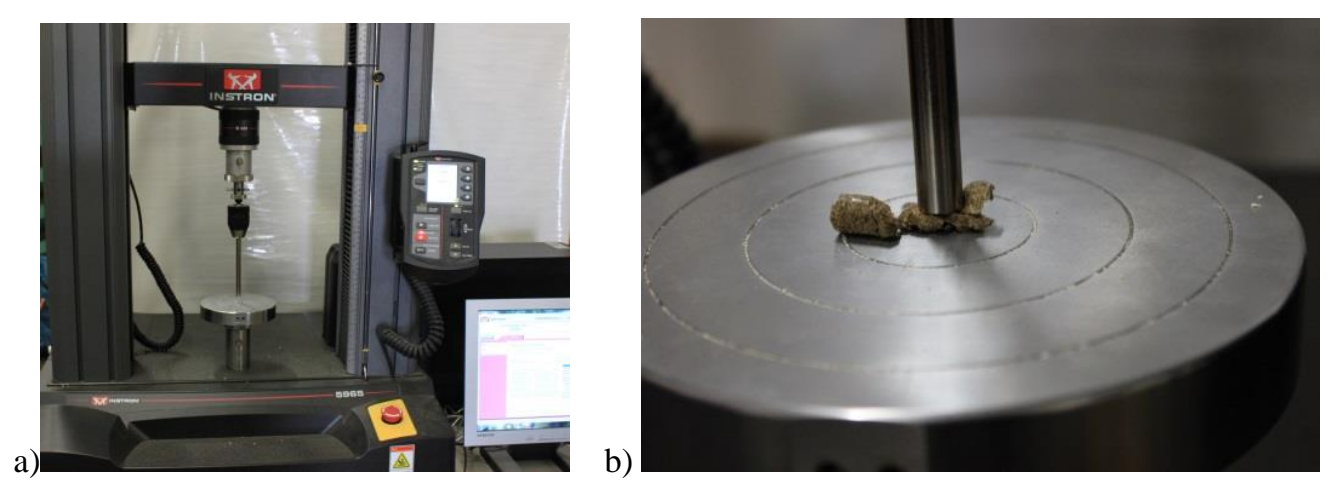

Figure 1. Material properties' testing equipment Instron 5960: a) general view; b) view of pellet‘s pressing process

The test results are recorded every 0.1 second until the pellet disintegrates completely exposed to the force. INSTRON equipment draws pellet resistance to compression characteristic of Young's modulus. Tests are repeated 5 times for pellets of each type of plant. Measurement error is $0.02 \%$.

After performed tests, research data will be processed by statistical - mathematical methods. Averages and their confidence intervals, estimated substantial difference in the threshold at $95 \%$ probability are calculated during data processing time (Kadžiulienè et al., 2014).

\section{RESULTS AND DISCUSSIONS}

Determination of herbal energy plant pellets biometric indicators. Moisture content has a great influence on biofuel heating values. Pellets quickly absorb ambient moisture, may swell, disintegrate and turn into its original state as before pelletizing. Dry raw materials with a moisture content up to max. $15 \%$ should be used for pellet production. Moisture content affects energetic indices of pellets, combustion efficiency and calorific value. Therefore, it is necessary to estimate biofuel's humidity.

Research has shown that moisture content of different types of pellets vary from each other, even if storage conditions of pellets were the same. The obtained moisture content of pellets is shown in Table 1.

Table 1. Herbal energy plant pellets moisture content

\begin{tabular}{|c|c|}
\hline Plant sort & $\begin{array}{l}\text { The sample average moisture content } \\
\qquad \mathrm{Wi}_{\mathrm{i}} \pm \Delta \mathrm{y}, \mathrm{c}\end{array}$ \\
\hline Elephant grass & $13.2 \pm 3.9$ \\
\hline Fibrous nettle & $13.1 \pm 1.3$ \\
\hline Common mugwort & $11.6 \pm 0.4$ \\
\hline Orchard grass & $10.0 \pm 6.4$ \\
\hline
\end{tabular}


According to the data obtained, it may be stated that the maximum moisture content is in elephant grass and fibrous nettle pellets $-13.1-13.2 \%$, and the lowest is in orchard grass pellets $-10 \%$. Assessing the moisture content of the pellets it appears that elephant grass and fibrous nettle pellets do not fully meet the requirements for production. The recommended humidity of pellets used for fuel should not exceed $12 \%$ (Sakalauskas et al., 2012).

Weight of pellets has also been determined, and the pellets' volume, density and dry matter content were calculated. The results of the computed values are presented in Table 2.

From the data of Table 2, it may be seen that the highest density is of orchard grass pellets $-983.8 \mathrm{~kg} \mathrm{~m}^{-3} \mathrm{DM}$ (dry matter), with small variation is common mugwort pellet density $-926.7 \mathrm{~kg} \mathrm{~m}^{-3} \mathrm{DM}$, and the lowest density is of elephant grass pellets $-619.3 \mathrm{~kg} \mathrm{~m}^{-3} \mathrm{DM}$.

The set bulk density of fibrous nettle pellets was $385.0 \mathrm{~kg} \mathrm{~m}^{-3} \mathrm{DM}$, fibrous nettle $-419.0 \mathrm{~kg} \mathrm{~m}^{-3} \mathrm{DM}$, the highest bulk density is of elephant grass $-478.0 \mathrm{~kg} \mathrm{~m}^{-3} \mathrm{DM}$.

Determination of pellet resistance to degradation. Resistance to degradation is an important parameter of pellets. This is especially important for pellets during transport and storage.

After resistance to degradation tests of selected biofuel pellets, we obtained results that are presented in Figures from 2 to 5 .

The test showed different herbal energy plants pellet deformation degradation start, and the force under which a pellet disintegrates completely.

Table 2. Herbal energy plant pellets physical properties

\begin{tabular}{|l|c|c|c|}
\hline \multirow{2}{*}{\multicolumn{1}{|c|}{ Plant sort }} & \multicolumn{3}{|c|}{ Pellet parameters } \\
\cline { 2 - 4 } & Mass, g & Volume, $\mathrm{m}^{3}$ & Density, $\mathrm{kg} \cdot \mathrm{m}^{-3}$ \\
\hline Elephant grass & 0.57 & $7.96 \cdot 10^{-6}$ & $\begin{array}{c}713.5 \pm 67.1 \\
(619.3 \pm 67.1 \mathrm{DM})\end{array}$ \\
\hline Fibrous nettle & 0.67 & $7.66 \cdot 10^{-6}$ & $\begin{array}{c}877.8 \pm 40.6 \\
(762.8 \pm 40.6 \mathrm{DM})\end{array}$ \\
\hline Common mugwort & 0.75 & $7.04 \cdot 10-6$ & $\begin{array}{c}1048.3 \pm 41.3 \\
(926.7 \pm 41.3 \mathrm{DM})\end{array}$ \\
\hline Orchard grass & 0.85 & $7.61 \cdot 10-6$ & $\begin{array}{c}1093.5 \pm 122.9 \\
(983.8 \pm 122.9 \mathrm{DM})\end{array}$ \\
\hline
\end{tabular}

Analyzing the fibrous nettle pellet deformation curve (Figure 2), we see that the pellet deformation started at $20 \mathrm{~N}$ force, and at $95 \mathrm{~N}$ force it disintegrated completely. Considering size of the force, its displacement and pellet moisture content $(13.1 \%)$, it is possible to decide that nettle pellets are sufficiently resistant to static force and do not disintegrate quickly even if moisture content was slightly higher than the requirements for the production of fuel.

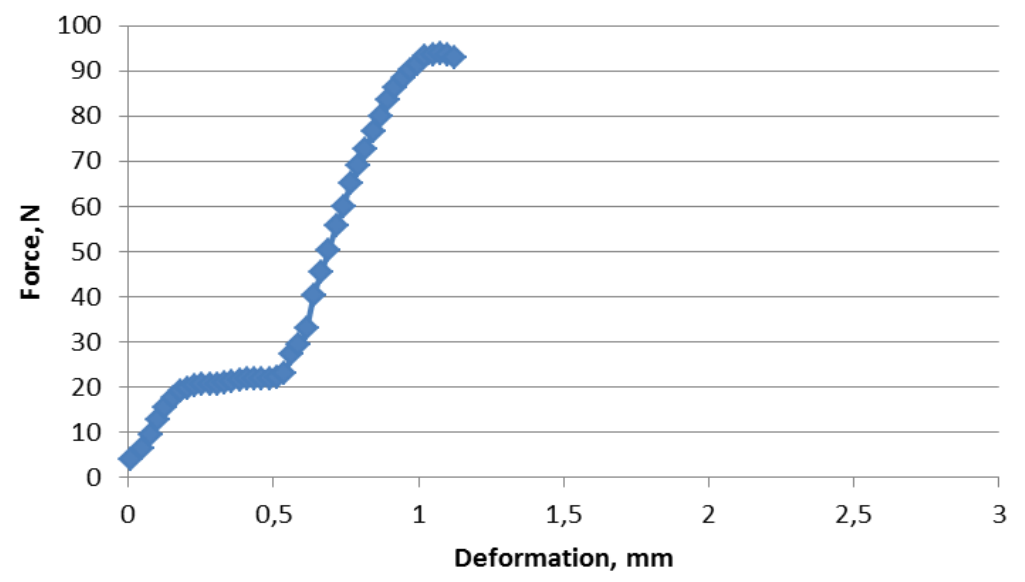

Figure 2. Deformation of fibrous nettle pellets and disintegration force

Elephant grass pellet deformation (Figure 3) started with the force of $5 \mathrm{~N}$, and disintegrated fully with the force 18 N. If comparing fibrous nettle (Figure 2) and elephant grass (Figure 3) pellets' resistance to deformation, we may notice that elephant grass pellets are less resistant to operating load than nettle. It is influenced by moisture content and density of the pellets. 


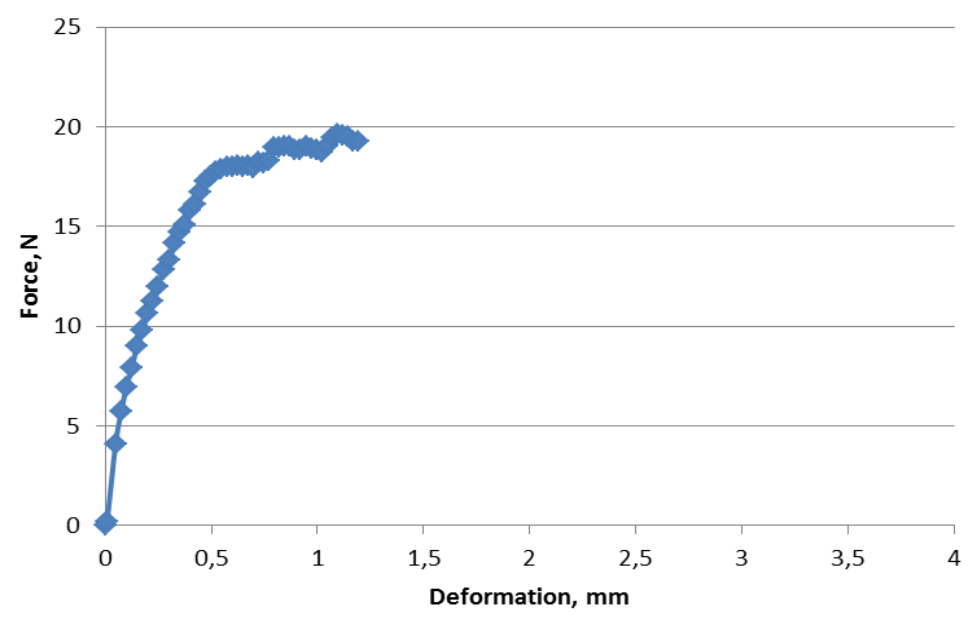

Figure 3. Deformation of elephant grass pellets and disintegration force

Biofuel pellets made from common mugwort are sufficiently resistant to the applied force. They disintegrate with the force of $98 \mathrm{~N}$ (Figure 4).

As it may be seen from research results shown in Figure 5, orchard grass pellets start deforming at $12 \mathrm{~N}$ force, and the pellet completely disintegrates when the force reaches $67 \mathrm{~N}$.

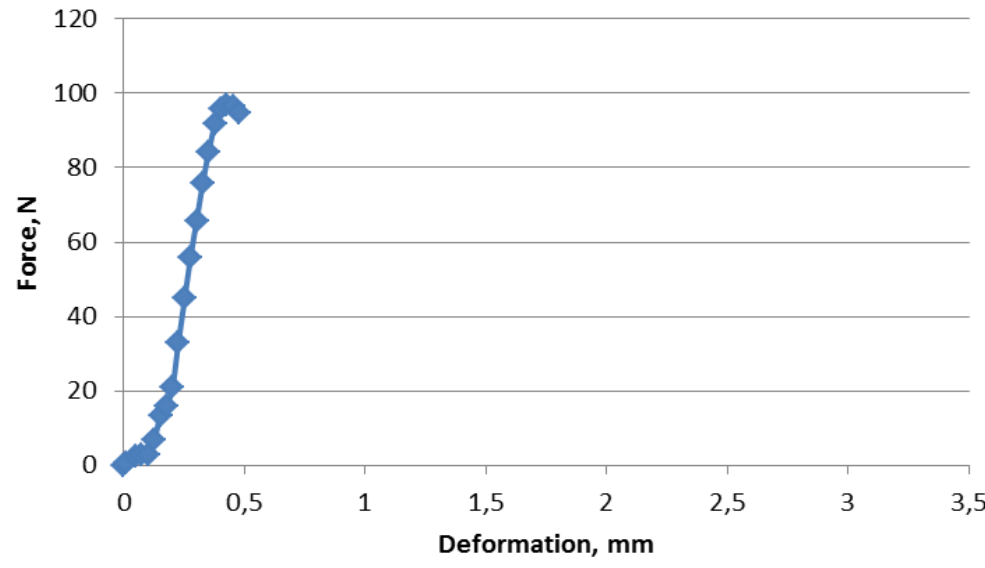

Figure 4. Deformation of common mugwort pellets and disintegration force

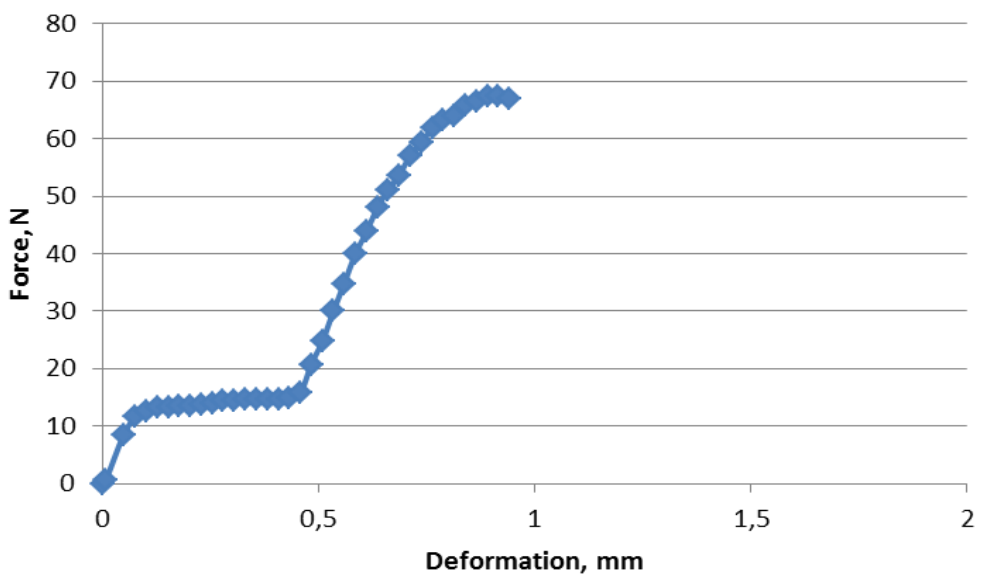

Figure 5. Deformation of orchard grass pellets and disintegration force

Experimental studies have established pellets resistance to deformation and fracture strength for each type of plant. The estimated average force $(F, N)$ needed to break a pellet and interval range $( \pm \Delta x)$.

The obtained results indicate that pellets made of common mugwort have the highest resistance to force applied. They disintegrate at $98 \mathrm{~N}$ force; fibrous nettle granules are less resistant - they disintegrate at the force about $95 \mathrm{~N}$. 
Elephant grass pellets have the lowest resistance to deformation and are likely to break down (with the lowest power) not reaching only $18 \mathrm{~N}$ force. $67 \mathrm{~N}$ force applied is needed for breaking up orchard grass pellets.

Summarizing the experimental results, it may be suggested that pellets made from elephant grass are of the lowest quality. So, it is not recommended to granulate these plants.

\section{CONCLUSIONS}

1. Having examined humidity of the produced pellets, it was found that the highest moisture content was in elephant grass and fibrous nettle pellets -13.1 to $13.2 \%$, while the smallest - orchard grass pellets, $10.0 \%$. Humidity of common mugwort pellets was $11.6 \%$. Evaluating pellets' moisture content in accordance with the requirements $(12 \%)$, it was found that elephant grass and fibrous nettle pellets humidity was approximately 1.1-1.2\% higher.

2. The highest pellet density of herbal energy plants was that of orchard $-983.8 \mathrm{~kg} \mathrm{~m}^{-3} \mathrm{DM}$ and common mugwort $-926.7 \mathrm{~kg} \mathrm{~m}^{-3} \mathrm{DM}$. Fibrous nettle pellets were of significantly lower density $-762.8 \mathrm{~kg} \mathrm{~m}^{-3} \mathrm{DM}$; density of elephant grass pellets was the lowest $-619.3 \mathrm{~kg} \mathrm{~m}^{-3} \mathrm{DM}$.

3. Herbal energy plant pellet resistance to deformation results show that the most resistant to external forces are pellets made of common mugwort. They break down to $98 \mathrm{~N}$ force. Other plants pellets disintegrate to smaller external force: fibrous nettle pellets - to $95 \mathrm{~N}$, orchard grass - to $67 \mathrm{~N}$ force. Elephant grass pellets are the least resistant to deformation and are likely to break down (at $18 \mathrm{~N}$ ).

\section{REFERENCES}

1. Sakalauskas, A., Jasinskas, A., Šarauskis, E., Vaiciukevičius, E., Kalinauskaite, S., Simonaitis, P. 2012. Substantiation of plant biomass (straw, grasses, woody plants, etc.) harvesting and preparation of biofuel technologies. Final report, Akademija, 108 p. (In Lithuanian).

2. Biekša, D., Janulis, M., Plankis, V. 2007. Assessment of straw fuel technology and further recommendations for their use and evaluation of the technology briquette production from chopped straw and herbaceous plant. Study report. Cowi Baltic, $50 \mathrm{p}$.

3. Verbickas, D., Juknys, R., Kleišmantas, A. 2013. The use of solid biofuels for Lithuanian heat production, future prospects and the impact on the environment. Energetics. Lithuanian Academy of Sciences, T. 59, No. 3, pp. 144-152 (In Lithuanian).

4. Straw fuel use in Lithuania. The Report of LUA Agricultural Engineering Institute, 06 October 2006, LUA, Kaunas (In Lithuanian).

5. Kryžiavičienė, A., Šarūnaitė, L., Stukonis, V., Dabkevičius, Z., Kadžiulienė, Ž. 2010. Evaluation of perennial mugwort (Artemisia vulgaris L. and Artemisia dubia Wall.) potential for biofuel production. Agricultural Sciences, T. 17, No. 1-2, pp. 32-40 (In Lithuanian).

6. Common mugwort. Report. 2014. Time, 05 April, 2014: 〈http://www.pollen.lt/index.php?m=95>.

7. Johnson, C. P. 1992. The Useful Plants of Great Britain. London: Robert Hardwicke, 324 p.

8. Jankauskienè, Z., Gruzdeviene, E. 2010. Evaluation of Cannabis sativa cultivars in Lithuania. Žemdirbysté=Agriculture, Vol. 97. No. 3, pp. 87-96.

9. Nettle patiently waiting the processors. 2012. Time: 05 December, 2013: < http://www.delfi.lt/verslas/kaimas/dilgeles-kantriailaukia-perdirbeju.d?id=58910229>.

10. Burbulis, N., Blinstrubienè, A., Masienè, R., Jankauskienè, Z., Gruzdevienè, E. 2012. Genotypic and growth regulator effects an organogenesis from hypocotyl explants of fiber Max (Linum usitatissimum L.). International Journal of Food, Agriculture \& Environment, Vol. 10, Iss. I, pp. 397-400.

11. Jasinskas, A., Scholz, V. 2008. Evaluation of technologies of plant biomass harvesting and preparation for fuel: coursebook. Raudondvaris, $74 \mathrm{p}$.

12. Christian, D. G., Poulton, P. R., Riche, A. B. 1997. The recovery of N-15 belled fertilizer applied to Miscanthus x gigantens. Biomass \&, Bioenergy, Vol. 7, Iss. 12, pp. 21-24.

13. My farm. Perennial grasses - solid biofuels. 2011/8. Time: 14 Mart 2011: <http://www.manoukis.lt/print_forms/print_st_z.php?s $=2535 \& \mathrm{z}=112$.

14. Introduction of the first Lithuania willow deck. Litbioma, 2013. Time: 26 April 2013: <www.biokuras.lt/lt/aktualijos/pristatytaspirmas-lietuvoje-gluosniu-pjovimo-agregatas.html>.

15. Jasinskas, A, Simonavičiūte, R, Šiaudinis, G, Liaudanskienè, I, Antanaitis, S, Arak, M, Olt, J. 2014. The assessment of common mugwort (Artemisia vulgaris L.) and cup plant (Silphium perfoliatum L.) productivity and technological preparation for solid biofuel. Žemdirbystè-Agriculture, Vol. 101, No. 1, pp. 19-26.

16. Kadžiulienė, Ž., Jasinskas, A., Zinkevičius, R., Makarevičienè, V., Šarūnaite, L., Tilvikienė, V., Šlepetys, J. 2014. Miscanthus biomass quality composition and methods of feedstock preparation for conversion into synthetic diesel fuel. Žemdirbyste $=$ Agriculture, Vol. 101, No. 1, pp. 27-34. 